\title{
Human skin retention and penetration of a copper tripeptide in vitro as function of skin layer towards anti-inflammatory therapy
}

\author{
Jurij J. Hostynek · Frank Dreher · Howard I. Maibach
}

Received: 3 February 2010/Revised: 28 April 2010/Accepted: 29 April 2010/Published online: 13 August 2010

(C) The Author(s) 2010. This article is published with open access at Springerlink.com

\begin{abstract}
Objective and design The skin retention and penetration characteristics of copper applied as glycyl-L-histidyl-Llysine cuprate diacetate were evaluated in vitro in order to assess the potential for its transdermal delivery as antiinflammatory agent.

Materials and methods Flow-through diffusion cells with $1 \mathrm{~cm}^{2}$ exposure area were used under infinite dose conditions. $0.68 \%$ aq. Copper as a tripeptide was applied on isolated stratum corneum, on heat-separated epidermis and on dermatomed skin. Receptor fluid collected over $48 \mathrm{~h}$ in $4 \mathrm{~h}$ intervals was analyzed by inductively coupled plasma mass spectrometry for copper in tissues and receptor fluid. Results The permeability coefficient of the compound through dermatomed skin was $2.43 \pm 0.51 \times 10^{-4} \mathrm{~cm} / \mathrm{h}$; $136.2 \pm 17.5 \mu \mathrm{g} / \mathrm{cm}^{2}$ copper permeated $1 \mathrm{~cm}^{2}$ of that tissue over $48 \mathrm{~h}$, while $82 \pm 8.1 \mu \mathrm{g} / \mathrm{cm}^{2}$ of copper were retained there as depot.

Conclusions Applied tansdermally as the tripeptide on human skin ex vivo, copper permeated the skin and was also retained in skin tissue in amounts potentially effective for the treatment of inflammatory diseases.
\end{abstract}

Keywords Absorption - Arthritis - Bioavailability · Copper complex $\cdot$ Depot $\cdot$ Inflammation

Responsible Editor: Michael Parnham.

J. J. Hostynek ( $\square)$ · F. Dreher · H. I. Maibach Department of Dermatology, UCSF School of Medicine,

University of California San Francisco, Surge 110,

San Francisco, CA 94143-0989, USA

e-mail: jurij.hostynek65@gmail.com

\section{Introduction}

Acute and chronic inflammation are characterized by changes in the metabolism of copper and by a pronounced responsiveness to therapy with copper compounds $[1,2]$. The copper content and ceruloplasmin activity of serum are significantly elevated above normal values in inflammatory diseases in humans and laboratory animals, and copper in widely different chemical forms is used as therapeutic agent in therapy for chronic and acute inflammation [2]. The rise in total serum copper measured in inflammation is held to represent the natural anti-inflammatory response of the organism itself. The responsiveness of inflammatory disorders to copper supplementation suggests that the control exerted by endogenous copper on inflammation is susceptible to enhancement by exogenous sources. When copper complexes were administered subcutaneously in experimentally inflamed animals the reduction in inflammation was proportional to total amount of copper injected [3].

While for nearly three-quarters of a century water soluble gold salts have been administered for their antiinflammatory properties, most effective among them gold thiomalate, particularly to relieve the symptoms of juvenile and adult rheumatoid arthritis [4], just how the metal exerts its anti-arthritic effect is not clear as it does not have a known biological function itself. Also, since the inception of systemic therapy using gold compounds the incidence of allergic skin reactions to the metal has been remarkably high, attributed to induced hypersensitivity [5]. However, recently Stoyanov and Brown [6] attributed an indirect role played by gold. They found that it specifically binds to a copper-activating protein, thus turning on production of a protein pump involved in copper transport thus mobilizing endogenous copper reserves stored mostly in liver and 
muscle. The biological effect of gold anti arthritic drugs may thereby consist in their effect on copper management in eukaryotic systems.

We investigated possible transdermal dosing of copper as the alternative to what so far has been the therapy for inflammatory disorders relying on intra articular or intra muscular injection of drugs which comports considerable patient discomfort.

Data on human skin penetration by copper compounds are scarce. The percutaneous absorption of copper from copper chloride and copper sulfate were investigated in vitro on human skin by Pirot et al. [7]. Formulated for therapeutic purposes, the salts were compounded with zinc chloride and zinc sulfate in petrolatum and two aqueous gels. For both the apparent permeability coefficients Kp were similar: $3.2-4.5 \times 10^{-6} \mathrm{~cm} / \mathrm{h}$. Extensive investigations conducted over years by Pickart into the multiple functions of the human tripeptide glycidyl-L-histidyl-Llysine as its copper $2+$ complex (GHK-Cu), recently reviewed [8], made that molecule an obvious choice for our skin penetration study.

Using a model membrane made of stratum corneum lipids, Mazurowska had suggested that copper peptides, and GHK-Cu in particular, might permeate skin [9]. However, experiments using skin models generally underestimate absorption since the composition of model membranes does not reflect the structure of the stratum corneum, a heterogeneous, multi component membrane, nor does it account for the high hydrophilicity of GHK-Cu which may determine an idiosyncratic path of diffusion [10, 11]. Orth [12] and Finkey [13] measured uptake of copper into superficial facial skin strata in vivo when applying GHK-Cu for cosmetic purposes, but to date bioavailability of copper was not studied quantitatively using human skin ex vivo. Therefore, evidence that copper does penetrate the skin in any form is so far based on its observed effects only: anti-inflammatory activity by topical application of copper complexes was shown in animals by Brown [1], by Sorenson in man [2], and has extensively been reviewed by Milanino [14].

\section{Materials and methods}

\section{Materials}

The permeant was GHK-Cu $(\mathrm{Ac})_{2}$, received from the ProCyte Corp. (Kirkland, WA). It was not analyzed for stoichiometric purity since, in several studies, copper complexes in a physiological environment were subject to de-complexation and rearrangement, depending on $\mathrm{pH}$ and complex stability constants $[15,16]$. Those investigations indicated the presence of multiple species for
GHK-Cu (e.g., tri- and hexa-peptide) in solutions, together with copper-free oligopeptide. Copper as a transition metal of variable oxidation states has the ability to form complexes with different geometries and stability. Here the test compound is summarily referred to as GHK-Cu. Concentrations are reported in terms of copper per $\mathrm{ml}$ of solution.

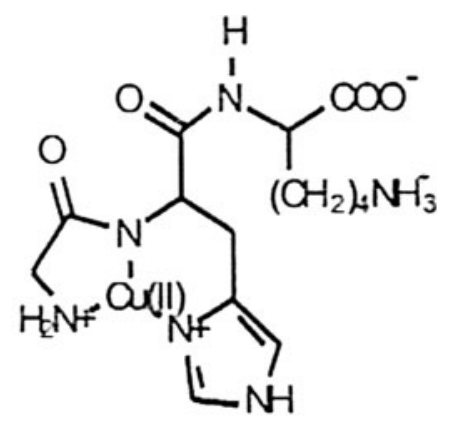

\section{$+2 \mathrm{CH}_{3} \mathrm{COO}^{\circ}$}

Chemical: Glycyl-L-histidyl-L-lysine copper cuprate, diacetate GHK$\mathrm{Cu}(\mathrm{Ac})_{2}$, Formula: $\mathrm{C}_{18} \mathrm{H}_{29} \mathrm{CuN}_{6} \mathrm{O}_{8}$

Experimental design

In vitro (a.k.a. ex vivo) skin diffusion studies were conducted with GHK-Cu at $0.68 \%$ aq. concentration using glass cells to mimic in vivo permeant flux. Copper depot formation and penetration was studied using:

Isolated stratum corneum (Experiment A)

Entire epidermis, including stratum corneum (experiment B)

Split thickness skin comprising stratum corneum, epidermis and underlying dermis tissue (experiment $\mathrm{C}$ )

Tissue preparation

Human cadaver skin was obtained from the Northern California Transplant Bank (San Rafael, CA) and stored in a freezer $\left(-20^{\circ} \mathrm{C}\right)$ until use. All experiments were performed within 2 months after freezing. Subjects were 3 Caucasian, aged 21-53 years, and both genders were represented.

Split thickness skin (entire epidermis with a portion of the dermis) was obtained by use of a dermatome targeted to $500 \mu \mathrm{m}$ and stored $\left(-20^{\circ} \mathrm{C}\right)$ until use.

Entire epidermis, (isolated epidermis including stratum corneum), was obtained by heat separation $\left(60^{\circ} \mathrm{C}\right)$ from underlying dermis tissue and stored $\left(-20^{\circ} \mathrm{C}\right)$ until use.

Isolated stratum corneum was obtained from isolated epidermis which was placed on Whatman paper soaked in a 
$0.05 \%$ w/w trypsin Type III (from bovine pancrease, Sigma Chemical, St. Louis, USA) solution in $0.15 \mathrm{M}$ phosphate buffered saline (PBS, pH 7.4, Sigma) for $2 \mathrm{~h}$ at $37^{\circ} \mathrm{C}$. Remaining trypsin activity was blocked by submerging the stratum corneum sheet in $0.05 \% \mathrm{w} / \mathrm{w}$ trypsin inhibitor Typed II (from soybean, Sigma Chemicals, St. Louis, USA), then the stratum corneum sheet washed twice in purified water, dried and stored above silica gel at room temperature.

\section{Diffusion experiment}

Ex vivo skin tissue was obtained from three donors. Replicates were run on tissue from the same donor. Glass low volume flow cells with $0.8 \mathrm{~cm}^{2}$ exposure area were kept at $37^{\circ} \mathrm{C}$. Receptor fluid was collected over $48 \mathrm{~h}$ in $4 \mathrm{~h}$ intervals. Cells were mounted in the wells of aluminum cell holder (Stratacor, Richmond, CA), whose internal channels were perfused with water at $37^{\circ} \mathrm{C}$ from a circulating water bath, and holders mounted on a fraction collector. Distilled water containing $1 \mathrm{ml} / \mathrm{l}$ of gentamicin sulfate solution (100 mg/ml, Sigma, St. Luis, MO) was pumped through the cells at approximately $2 \mathrm{ml} / \mathrm{h}$ with a 12 channel peristaltic pump. Tissues were cut into circles with a biopsy punch $\left(1 \mathrm{~cm}^{2}\right)$, mounted on the diffusion cells and the donor chambers clamped in place.

To test for tissue integrity, prior to the experiment with tissue discs clasped in place the peristaltic pump was run at $10 \mathrm{rpm}$ generating back pressure in the receptor cells (five times the normal pressure) for $2 \mathrm{~h}$ to check for leakers, which were eliminated.

About $1 \mathrm{ml}$ of test solution was placed in the donor chambers, closed with ground glass stoppers and sealed with Parafilm to prevent donor solution evaporation. Eight cells were typically set up at one time, with four cells used for each of two treatments. Receptor fluid samples were collected in a $20-\mathrm{ml}$ polyethylene screw-cap scintillation (LSC) vials (Maxi-vial, Packard Instruments, Downers Grove, IL). At completion of an experiment the donor cell contents were pipetted into LSC vials. The donor chamber and skin surface was rinsed $(3 \times 2 \mathrm{ml})$ with distilled water and the rinse saved in the LSC vials with polyethylene cap liners (PerkinElmer, Shelton, CT). Nitric acid (0.75 g) was added to each skin sample and the vial heated $\left(50-60^{\circ} \mathrm{C}\right)$ to effect dissolution. After cooling, samples were diluted with $15 \mathrm{ml}$ distilled water to give a final nitric acid concentration of $3.5 \%$ required for inductively coupled plasma mass spectroscopy analysis. Samples were filtered and stored at $4{ }^{\circ} \mathrm{C}$.

Analytical methodology

For original copper levels, portions of isolated stratum corneum, isolated epidermis, as well as split thickness dermis were analyzed to determine the increment retained there during diffusion. Following the diffusion experiment C, split thickness skin was also separated into epidermis and dermis (entire separated epidermis and separated dermis) for analysis of tissue depot formation in the experiment.

Experimental details and results are reported in terms of copper, analyzed by inductively coupled plasma mass spectroscopy. It is a technique applicable to $\mu \mathrm{g} / \mathrm{l}$ (ppb) concentrations of many elements in aqueous medium upon appropriate sample preparation of biological materials. Reliability of the method for elemental analysis is based upon multi-laboratory performance compared with that of either furnace atomic absorption spectroscopy or ICP-AES. Normal instrument detection limit for copper can be anticipated at $0.5 \mathrm{ppb}$.

Inductively coupled plasma mass spectroscopy analyses were performed by DuPont Analytical Solutions, Wilmington, DE. There samples were prepared by diluting 1:10 (volume/volume), using $2 \% \mathrm{HNO}_{3}$ immediately prior to analysis. The ICP-MS equipment used was an Agilent 7500c, operated under helium collision gas mode. The instrumental detection limit was $<100 \mathrm{pg} / \mathrm{ml}$ copper. Standard solutions were prepared by diluting a $1,000-\mu \mathrm{g} / \mathrm{ml}$ copper stock solution with $2 \% \mathrm{HNO}_{3}$. Two separate (low concentration and high concentration) six-point external calibration curves $\left(r^{2}>0.999\right)$ were used for quantitation of both copper isotopes (63 and $65 \mathrm{Cu}$ ) with $89 \mathrm{Y}$ used as an internal standard. The low concentration calibration curve was constructed from $1,2,5,10$, and $20 \mathrm{ng} / \mathrm{ml} \mathrm{Cu}$ standards and the high concentration calibration curve was from 20, 100, 1,000, 5,000, and 10,000 ng/ml copper standards. The instrument was calibrated using the five standards above, and the samples bracketed between the standards without extrapolation either below the calibration curve nor above it.

\section{Data analysis}

The permeability coefficient $\mathrm{Kp}(\mathrm{cm} / \mathrm{h})$ is the ratio of steady state flux and the donor concentration multiplied by the membrane area covered. The flux $\left(\mu \mathrm{g} / \mathrm{cm}^{2} / \mathrm{h}\right)$ at steady state (Jss) is the permeant value per membrane area per hour following the initial lag time which is the delay measured for the permeant to reach a constant value Jss. The Kp was calculated from the permeation rate at steady state flux Jss, determined from the linear portion of the amount permeated versus time profile. The permeation profile of copper for each tissue layer was plotted against time.

The tissue copper levels reported from diffusion experiments were corrected for endogenous levels determined prior to the experiments. 


\section{Results}

Skin permeability coefficients (Kps) for the copper tripeptide ranged from $3 \times 10^{-7} \mathrm{~cm} / \mathrm{h}$ through isolated epidermis (Table 1, Exp. B), to $5.59 \times 10^{-3} \mathrm{~cm} / \mathrm{h}$ through isolated stratum corneum (Table 1, Exp. A).

Lag times measured from $2 \mathrm{~h}$ on isolated stratum corneum and spilt thickness skin (Table 1, Exp. A, C), to $7 \mathrm{~h}$ on isolated epidermis (Table 1, Exp. B).

Copper collected in the receptor fluid in $48 \mathrm{~h}$ ranged from $0.60 \pm 0.21 \mu \mathrm{g} / \mathrm{cm}^{2}$ or $0.006 \pm 0.001 \%$ of the dose through isolated epidermis (Exp. B; Table 2), to $136.2 \pm 17.5 \mu \mathrm{g} / \mathrm{cm}^{2}$ or $2.0 \pm 0.31 \%$ through split thickness skin (Exp. C, Table 2).

About $290 \pm 69 \mu \mathrm{g} / \mathrm{cm}^{2}$ Copper was retained in the stratum corneum tissue, a 438-fold increase over baseline levels (Table 3, Exp. A). Isolated epidermis retained $61.1 \pm 13.1 \mu \mathrm{g} / \mathrm{cm}^{2}$, a factor of 165 over base line (Table 3, Exp. B), and dermatomed skin $53 \pm 8.1 \mu \mathrm{g} / \mathrm{cm}^{2}$ or 31 times baseline (Table 3, Exp. C).

\section{Discussion}

This study evaluates absorption and skin retention of a copper tripeptide in separate skin compartments: the stratum corneum, entire epidermis and split thickness skin.

The amount of copper deposited from the tripeptide in the stratum corneum as well as in the entire epidermis and dermis is significant. For instance, about a 400-fold increase over baseline was retained in the isolated stratum corneum. Such high tissue retention of copper may be attributed to intradermal decomplexation and re-binding to various endogenous amino acids of higher nucleophilic donor capacity than the original ligand.

Assessing whether permeant retained in skin tissues, the stratum corneum in particular, eventually becomes available systemically is an issue of ongoing discussions. Reservoir formation in the course of in vitro studies has been addressed [17]. Retained drug may be lost to natural desquamation, limiting its eventual systemic availability. On closer analysis, however, it has been found that the

Table 1 Copper skin penetration as function of skin strata from aq. GHK-Cu solution. Skin permeability coefficients $(\mathrm{Kp})$, steady-state skin penetration flux and lag time for copper tripeptide are shown for

\begin{tabular}{llccc}
\hline Exp. & Skin strata & $\mathrm{Kp} \times 10^{4}(\mathrm{~cm} / \mathrm{h}) \pm \mathrm{SD}$ & Flux $\left(\mu \mathrm{g} / \mathrm{cm}^{2} / \mathrm{h}\right) \pm \mathrm{SD}$ & $\mathrm{Lag}$ time $(\mathrm{h})$ \\
\hline $\mathrm{A}$ & Isolated stratum corneum $(n=3)$ & $55.9 \pm 13.2$ & $38 \pm 9$ & 2 \\
$\mathrm{~B}$ & Isolated epidermis $(n=3)$ & $0.003 \pm 0.0006$ & $0.002 \pm 0.0004$ & 7 \\
$\mathrm{C}$ & Dermatomed skin $(n=8)$ & $2.43 \pm 0.51$ & $1.7 \pm 0.35$ & 2
\end{tabular}

Difference in values were considered significant $(P<0.05)$

Table 2 Human skin retention and penetration of copper in function of skin strata

\begin{tabular}{llllllll}
\hline Exp. & Skin strata & $\begin{array}{l}\text { Donor } \\
\text { recovered }\end{array}$ & $\begin{array}{l}\text { Stratum } \\
\text { corneum }\end{array}$ & $\begin{array}{l}\text { Total } \\
\text { epidermis }\end{array}$ & $\begin{array}{l}\text { Dermatomed } \\
\text { skin }\end{array}$ & Receptor fluid & $\begin{array}{l}\text { Total \% } \\
\text { recovered }\end{array}$ \\
\hline A & Isolated stratum corneum $(n=3)$ & $(79 \pm 13)$ & $290.3 \pm 69$ & NA & NA & $2110 \pm 589(19.85 \pm 3.9)$ & $(98 \pm 27)$ \\
B & Total epidermis $(n=3)$ & $(94 \pm 12)$ & ND & $61.1 \pm 13.1$ & NA & $0.60 \pm 0.21(0.006 \pm 0.001)$ & $(95 \pm 12)$ \\
C & Dermatomed skin $(n=8)$ & $(91 \pm 14)$ & ND & ND & $82 \pm 8.1$ & $136.2 \pm 17.5(2.0 \pm 0.31)$ & $(94 \pm 7)$ \\
\hline
\end{tabular}

Amount of copper found in the stratum corneum, total epidermis, dermatomed skin, receptor fluid, donor compartment as well as the total amount recovered are given in $\mu \mathrm{g}$ per $\mathrm{cm}^{2}$ and in percentages of the applied copper dose (in brackets) after $48 \mathrm{~h}$. Difference in values were considered significant $(P<0.05)$

$N A$ not applicable; $N D$ not determined

Table 3 Copper reservoir in skin layers vs. original levels from $0.68 \%$ aq. GHK-Cu at $48 \mathrm{~h}$

\begin{tabular}{lccc}
\hline Skin compartment & $\mathrm{Cu}$ at $0 \mathrm{~h}\left(\mu \mathrm{g} / \mathrm{cm}^{2}\right)$ & $\mathrm{Cu}$ at $48 \mathrm{~h}\left(\mu \mathrm{g} / \mathrm{cm}^{2}\right)$ & Increase vs. $0 \mathrm{~h}$ \\
\hline Isolated stratum corneum (Exp. A) & $0.68 \pm 0.3 ; n=3$ & $290 \pm 69 ; n=3$ & $438 \times$ \\
Total epidermis (Exp. B) & $0.37 \pm 0.2 ; n=3$ & $61.1 \pm 13.1 ; n=3$ & $165 \times$ \\
Dermatomed skin (Exp. C) & $1.72 \pm 0.5 ; n=8$ & $53 \pm 8.1 ; n=8$ & $31 \times$ \\
\hline
\end{tabular}

Baseline copper levels and copper levels after $48 \mathrm{~h}$ exposure to $0.68 \%$ copper peptide solution are given for stratum corneum, total epidermis and split thickness (dermatomed) skin. The difference in values were considered significant $(P<0.05)$ 
fraction of chemical sloughing off versus the part that becomes systemically available depends on the ratio of lag time to the turnover time for the stratum corneum [18]. Accordingly, at least $80 \%$ of the amount in the stratum corneum will become available if the lag time for penetration through that tissue is less than approximately $16 \mathrm{~h}$ This corresponds to $5 \%$ of the typical stratum corneum turnover time of 14 days. Consequently, based on our results where lag times ranged from 2 to $7 \mathrm{~h}$, the copper retained in the stratum corneum has the potential to become systemically available also. As a result of the experiment with dermatomed skin, by topical application of GHK-Cu under the present conditions $200-250 \mu \mathrm{g} / \mathrm{cm}^{2}$ copper may become systemically available. Since the experiment was conducted ex vivo, it is possible that even larger amounts will be retained in the deeper dermal tissue in vivo, to be followed by further diffusion.

The permeation rate of $\mathrm{GHK}-\mathrm{Cu}$ through stratum corneum seems high, the highest of all three skin strata studied, consistent with a model of porous transport. Appendageal penetration is considered to be one, if not the predominant pathway for the diffusion of multipolar ions $[19,20]$. In addition, the high penetration level through isolated stratum corneum can be attributed to the absence of retention in underlying skin, which would limit copper penetration.

The marked hydrophilicity of the copper tripeptide with a pseudo $\log \mathrm{P}_{\text {ow }}=-4.5$, the quotient saturated n-octanol/ saturated aqueous solution [21], is reconcilable with shunt penetration typical for highly hydrophilic solutes such as salts. Significant penetration through appendages can occur within minutes following exposure in contrast to nonappendageal pathways [22, 23].

The Kps of GHK-Cu through epidermis and dermatomed skin were lower by about one order of magnitude. Restriction of the pores area may be the cause for the discrepancy in those diffusion constants when compared to stratum corneum alone.

The present study indicates that topical administration of copper as the tripeptide may offer an effective alternative to injection. Since a realistic dimension for topical application of $\mathrm{GHK}-\mathrm{Cu}$ as a patch may cover $10 \mathrm{~cm}^{2}$ of skin, based on our results $1.36 \mathrm{mg}$ of copper would then become available over $48 \mathrm{~h}$.

When administering copper for therapeutic purposes, the potential for toxicity should be considered. There is ample evidence that the copper ion released will be subject to the highly efficient homeostatic control in eukaryotic organisms, preventing its circulation at toxic levels. Free ionic copper, a relatively toxic metal, is moderated to the minimum levels sufficient for physiological needs, reported in the range of $10^{-11}$ to $10^{-19}$ mol estimated in plasma, by binding to ceruloplasmin and metallothionein [24]. The dynamic equilibrium between ceruloplasmin and metallothionein stored in liver tissue prevents toxic accumulation of free copper ion in mammals [25]. That hepatic reservoir is released slowly back into the blood as ceruloplasmin and copper metallothionein in response to inflammation due to injury or arthritis [26]. The average level of bound copper in human control plasma is $1.12 \mu \mathrm{g} / \mathrm{ml}$ [27]; in arthritic patients it is $1.40 \mu \mathrm{g} / \mathrm{ml}$ [28]. A therapeutically effective copper level in inflammation cannot be assessed in definite terms, however, because copper status induced in response to inflammatory diseases in humans varies depending on target organ [14]. In order to document the tolerability of metallic copper in contact with the skin, which must first be oxidized in order to penetrate, Gorter examined absorption and tolerance of metallic copper-containing ointments on human volunteers over a period of several weeks. Copper analysis in serum showed that levels had increased significantly above control levels, without overt untoward effects, either in the skin or systemically, following application of ointments containing up to $20 \%$ of the metal in its elemental form [29].

\section{Conclusions}

The results obtained show that a topical organic copper complex such as $\mathrm{GHK}-\mathrm{Cu}$ may be an alternative to copper delivery by injection, also potentially providing a skin reservoir likely to become available over time. This effect warrants further development toward transdermal delivery of the anti-inflammatory agent, especially when considering GHK as ligand, a nature identical carrier tripeptide [8]. In the past, several laboratories demonstrated local and systemic anti-inflammatory activity of copper compounds by oral, ip, iv, and particularly subcutaneous administration. Having shown permeation of the skin barrier by $\mathrm{GHK}-\mathrm{Cu}$ in a therapeutically effective dose, however, application of this principle to transdermal dosing may now offer a realistic alternative to current, traditional therapeutic routes and agents. Taking our results a step further, one can optimize the controlled release of copper for antiinflammatory therapy using patch technology with well-designed formulations. This would present a welcome alternative to current methods, which rely on corticosteroids, NSAIDs, chrysotherapy, or the family of COX-2 cyclooxygenase inhibitors as analgesics and anti-inflammatory agents, since most of them are associated with untoward side effects [30-32], some of them causing considerable discomfort, depending on the mode of administration.

That a deficit in this essential element may be substantially corrected by choosing an appropriate cupriphore represents a significant outcome of our endeavors towards 
alleviating rheumatoid arthritis and similar musculoskeletal conditions afflicting the general population.

Acknowledgments We express our appreciation for the guidance received from the late Roberto Milanino, MD, of the University of Verona, who brought insight into the biological relevance of our research and to whose memory we dedicate this manuscript. We thank Len Patt of the ProCyte Corporation (Redmond, WA) for making a complimentary sample of the copper tripeptide available for our investigation. We thank Larry Ryan, DuPont Analytical Solutions (Wilmington, DE) for supervising inductively coupled plasma mass spectroscopy analyses, and Jeannette Woodward for their execution. No external funding was involved in the pursuit of this research.

Open Access This article is distributed under the terms of the Creative Commons Attribution Noncommercial License which permits any noncommercial use, distribution, and reproduction in any medium, provided the original author(s) and source are credited.

\section{References}

1. Brown DH, Smith WE, Teape JW, Lewis AJ. Anti-inflammatory effects of some copper complexes. J Med Chem. 1980;23: 729-34.

2. Sorenson JRJ. Copper chelates as possible active forms of the antiarthritic agents. J Med Chem. 1979;19:135-48.

3. Jackson GE, Mkhonta-Gama L, Voye A, Kelly M. Design of copper-based anti-inflammatory drugs. J Inorg Biochem. 2000;79:147-52.

4. Browning JS, Rice RM, Lee WV, Baker LM. Gold therapy in rheumatoid arthritis. N Engl J Med. 1947;237:428-31.

5. Hostynek JJ. Gold: an allergen of growing significance. Food Chem Toxicol. 1997;35(8):835-44.

6. Stoyanov JV, Brown NL. The escherichia Coli copper-responsive copA promoter is activated by gold. J Biol Chem. 2005;278:1407.

7. Pirot F, Millet J, Kalia YN, Humbert P. In vitro study of percutaneous absorption, cutaneous bioavailability and bioequivalence of zinc and copper from five topical formulations. Skin Pharmacol. 1996;9:259-69.

8. Pickart L. The human tripeptide GHK (Glycyl-L-Histidyl-LLysine). $\mathrm{T}$ he copper switch, and the treatment of degenerative conditions of aging. Anti-Aging Therapeutics vol. XI. 2009; 301-312.

9. Mazurowska L, Nowak-Buciak K, Mojski M. ESI-MS study of the mechanism of glycyl-L-histidyl-L-lysine-Cu(II) complex transport through model membranes of stratum corneum. Talanta. 2007;72:650-4.

10. Schaefer H, Redelmeier TE. Permeability properties of the stratum corneum. In: Skin barrier. Principles of percutaneous absorption. New York: Karger; 1996. pp. 87-117.

11. Schaefer H, Lademann J. The role of follicular penetration-a differential view. Skin Pharmacol Appl Physiol. 2001;14(Suppl 1): 23-7.

12. Orth DS, Widjaja J, Ly L, Cao N, Shapiro WB. Stability of skin persistence of topical products. Cosmet Toilet. 1998;113:51-63.

13. Finkey M, Appa Y, Bhandarkar S. Copper peptide and skin. In: Elsner P, Maibach HI, editors. Cosmeceutical and active cosmetics. New York: Taylor and Francis; 2005. p. 550-64.

14. Milanino R, Buchner V. Copper: role of the endogenous and exogenous metal on the development and control of inflammatory processes. Rev Environ Health. 2006;21:153-215.
15. Freedman JH, Pickart L, Weinstein B, Mims WB, Peisach J. Structure of the glycidyl-L-histidyl-L-lysine-copper(II) complex in solution. Biochemistry. 1982;21:4540-4.

16. Conato C, Gavioli R, Guerrini R, Kozlowski H, Mlynarz P, Pasti C, Pulidori F, Remelli M. Copper complexes of glycyl-histidyllysine and two of its synthetic analogues: chemical behaviour and biological activity. Biochim Biophys Acta. 2001;1526: 199-210.

17. Yourick JJ, Koenig ML, Yourick DL, Bronaugh RI. Fate of chemicals in skin after dermal application: does the in vitro skin reservoir affect the estimate of systemic absorption? Toxicol Appl Pharmacol. 2004;195:309-20.

18. Reddy MB, Bunge AL. In: Bronaugh RL, Maibach HI, editors. Percutaneous absorption, 4th edn. New York: Marcel Dekker; 2005. pp. 165-176.

19. Potts RO, Guy RH, Francoeur ML. Routes of ionic permeability through mammalian skin. Solid State Ionics. 1992;53-56: $165-9$.

20. Mazzenga GC, Berner B, Jordan F. The transdermal delivery of zwitterionic drugs II: the flux of zwitterionic salts. J Contr Rel. 1992;20:163-70.

21. RCC. Determination of the partition coefficient (n-octanol/water) of copper tripeptide-1 (PC 1044). RCC Ltd, Environmental Chemistry \& Parmaceutical Division; $\mathrm{CH}-4452$ Ittingen/Switzerland; 2002.

22. Sznitowska M, Berner B, Maibach HI. Percutaneous penetration of multipolar ions: evidence for porous transport. Int J Pharm. 1995;123:41-5.

23. Lademann J, Otberg N, Richter H, Jacobi U, Schaefer H, BlumePeytavi U. Folliculaere Penetration-Ein entscheidender Penetrationsweg von topisch applizierten Substanzen. Hautarzt. 2003;54:321-3.

24. Furnival C, May PM, Williams DR. Models of low-molecularweight copper(II) complexing equilibria in relation to rheumatoid arthritis. In: Rainsford KD, Brune K, Whitehouse MW, editors. Trace elements in the pathogenesis and treatment of inflammation. Basel: Birkhäuser Verlag; 1981. pp. 241-257.

25. Cousins RJ. Absorption, transport, and hepatic metabolism of copper and zinc: special reference to metallothionein and ceruloplasmin. Physiol Rev. 1985;65:238-309.

26. Powanda MC. Systemic alterations in metal metabolism during inflammation as part of an integrated response to inflammation. Agents Actions 1981;Suppl 8:121-135.

27. Iyengar GV, Kollmer WE, Bowen HJM. The elemental composition of human tissues and body fluids. New York: Verlag Chemie; 1978.

28. Milanino R, Frigo A, Bamabara LM, Marrella M, Moretti U, Pasqualicchio M. Copper and zinc status in rheumatoid arthritis: studies on plasma, erythrocytes and urine, and relationship with disease activity markers and pharmacological treatment. Clin Exp Rheumatol. 1993;11:271-81.

29. Gorter RW, Butorac M, Cobian EP. Examination of the cutaneous absorption of copper after the use of copper-containing ointments. Am J Ther. 2004;11:453-8.

30. Wallace JL, Muscara MN. Selective cyclo-oxygenase-2 inhibitors: cardiovascular and gastrointestinal toxicity. Dig Liver Dis. 2001;33(Suppl 2S):21-8.

31. Szabo S, Spill WF, Rainsford KD. Non-steroidal anti-inflammatory drug-induced gastropathy. Mechanism and management. Med Toxicol Adverse Drug Exp. 1999;4:77-94.

32. Muscara MN, Vergnolle N, Lovren F, Triggle CR, Elliott SN, Asfaha S, Wallace JL. Selective cyclo-oxygenase-2 inhibition with celecoxib elevates blood pressure and promotes leukocyte adherence. Br J Pharmacol. 2000;129:1423-30. 